\title{
Peak inspiratory flow through Turbuhaler in acute asthma
}

\author{
P.H. Brown*, A.C.W.S. Ning**, A.P. Greening*, A. McLean**, G.K Crompton*
}

Peak inspiratory flow through Turbuhaler ${ }^{\circledR}$ in acute asthma. P.H. Brown, A.C.W.S. Ning, A.P. Greening, A. McLean, G.K Crompton. CERS Journals Ltd 1995.

ABSTRACT: Efficient use of dry powder inhalers, such as Turbuhaler ${ }^{\circledR}$, is dependent on the generation of adequate inspiratory flow. It is not clear whether patients with acute asthma are able to generate adequate flow.

Peak inspiratory flow (PIF) was measured through an empty Turbuhaler, and without this device, in 99 adults presenting to hospital with acute exacerbations of asthma. Where possible, patients were studied prior to nebulized bronchodilator therapy.

Mean (SD) forced expiratory volume in one second (FEV1) was 1.2 (0.7) L, forced vital capacity (FVC) 2.1(1.0) L and peak expiratory flow (PEF) 199 (92) L'min ${ }^{-1}$. PIF without Turbuhaler was $152(77) \mathrm{L}^{2} \mathrm{~min}^{-1}$ and correlated with PEF (r=0.69). PIF through Turbuhaler was $60(20) \mathrm{L} \cdot \mathrm{min}^{-1}$ and weakly correlated with PEF $(r=0.35)$, and with PIF without Turbuhaler $(r=0.43)$. Two patients failed to generate the minimum inspiratory flow $(30 \mathrm{~L} \cdot \mathrm{min})$ required for efficient use of Turbuhaler; both recorded $26 \mathrm{~L} \cdot \mathrm{min}^{-1}$.

Acute asthma is associated with considerable inspiratory, as well as expiratory airflow limitation. The relationship between inspiratory and expiratory airflow is not strong enough to predict whether patients with severe acute asthma will have difficulty using dry powder inhalers efficiently. Despite this, $98 \%$ of patients in this study generated inspiratory flow through Turbuhaler which would allow a therapeutically active amount of bronchodilator drug to be delivered to the airways.

Eur Respir J., 1995, 8, 1940-1941.
*Respiratory Medicine Unit, Western General Hospital, Edinburgh, UK. **Astra Clinical Research Unit, Edinburgh, UK.

Correspondence: G.K. Crompton Respiratory Medicine Unit Western General Hospital Edinburgh EH4 2XU UK

Keywords: Acute asthma peak inspiratory flow Turbuhaler

Received: December 51994 Accepted after revision August 41995
Dry powder inhalers (DPIs) such as Turbuhaler ${ }^{\circledR}$ are increasingly being used in preference to the conventional aerosol metered-dose inhaler, because patients find them easier to use [1] and they do not contain chlorofluorocarbon propellants and lubricants/surfactants. However, a potentially serious disadvantage is that their efficient use is dependent upon the generation of adequate inspiratory flow. This study was performed to establish whether patients presenting to hospital with acute asthma could generate sufficient peak inspiratory flow (PIF) through Turbuhaler to allow adequate drug delivery.

\section{Materials and methods}

Ninety nine patients (mean age 42 yrs, range 11-88 yrs; 63 females and 36 males) with acute asthma were studied within $30 \mathrm{~min}$ of admission. In all, the diagnosis of asthma had been previously established. They were either referred by their general practitioners or selfreferred via our Emergency Asthma Service, because of an acute exacerbation of asthma. Where possible, they were studied prior to administration of nebulized bronchodilator therapy. After written consent had been obtained, lung function was assessed using two spirometers (Vitalograph Compact, Vitalograph Ltd, Buckingham, UK).
Patients performed a maximal forced expiration immediately followed by a maximal forced inspiration. Peak expiratory flow (PEF), forced expiratory volume in one second (FEV1) and forced vital capacity (FVC) were derived from the expiratory limb of the flow-volume loop and PIF from the inspiratory limb. PIF through Turbuhaler (PIF-T) was measured during a maximal forced inspiration using another spirometer attached to an adaptor in which an empty Turbuhaler was mounted. Noseclips were used with both spirometers, the order of spirometer use was randomized and, for all variables, the best of two measurements was analysed.

Relationships between variables were analysed using Pearson product moment correlation tests. The study was approved by the Lothian Area Medical Ethics Committee.

\section{Results}

Mean (SD) expiratory flow values were: FEV1 1.2 (0.7) L (41\% predicted); FVC 2.1 (1.0) L (59\% pred); PEF 199 (92) $\mathrm{L} \cdot \mathrm{min}^{-1}$ (46\% pred). Mean PIF without Turbuhaler was 152 (77) $\mathrm{L} \cdot \mathrm{min}^{-1}$ (46\% pred) and 60 (16) $\mathrm{L} \cdot \mathrm{min}^{-1}$ through the inhaler. Only two patients were unable to achieve a PIF of $30 \mathrm{~L} \cdot \mathrm{min}^{-1}$ through Turbuhaler; both recorded $26 \mathrm{~L} \cdot \mathrm{min}^{-1}$. 


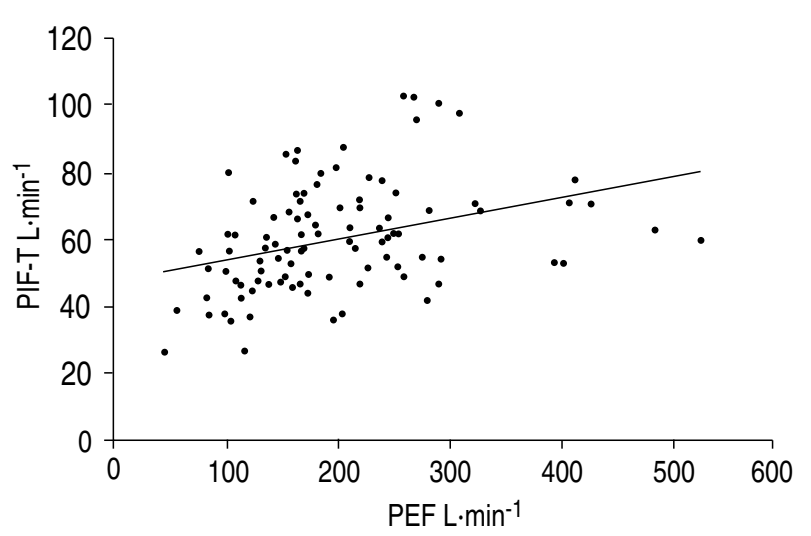

Fig. 1. - Relationship between peak inspiratory flow through Turbuhaler® $(\mathrm{PIF}-\mathrm{T})$ and peak expiratory flow $(\mathrm{PEF})$ in acute asthma $(n=99$; $\mathrm{r}=0.35 ; \mathrm{p}<0.01)$.

Significant $(\mathrm{p}<0.001)$ correlations were found between PEF and PIF ( $r=0.69)$ and FEV1 and PIF ( $r=0.57)$. Correlations between PEF and PIF-T (fig. 1) ( $\mathrm{r}=0.35$ ), FEV1 and PIF-T $(r=0.36)$, and between PIF and PIF-T $(r=0.43)$ were weak but still significant $(p<0.001)$. These correlations were minimally increased if analysis was confined to the 92 patients with $\mathrm{PEF}<350 \mathrm{~L} \cdot \mathrm{min}^{-1}$ (see below): PEF and PIF-T ( $\mathrm{r}=0.46)$; FEV1 and PIF-T ( $\mathrm{r}=$ 0.41); PIF and PIF-T ( $\mathrm{r}=0.51)$.

All 99 patients were treated with nebulized bronchodilators and systemic corticosteroids. Forty four patients received nebulized therapy in the ambulance travelling to hospital or in our emergency room just prior to study. At the time of measurements, a minority had already responded well to this treatment; hence, the seven patients with PEF $>350 \mathrm{~L} \cdot \mathrm{min}^{-1}$ shown in the figure. PIF-T values of the 55 patients who had not received nebulized therapy prior to the study were very similar to those who had been treated. All patients recovered uneventfully.

\section{Discussion}

In this study, patients with acute asthma had substantial inspiratory airflow limitation: mean PIF was lower than PEF, raising the possibility that severe airways obstruction might compromise effective use of dry powder inhalers. The small spiral channels in the mouthpiece of Turbuhaler allow disaggregation of drug particles by creating resistance to airflow. In our patients, the mean PIF through Turbuhaler $\left(60 \mathrm{~L} \cdot \mathrm{min}^{-1}\right)$ was $40 \%$ of that generated without any inspiratory resistance but was similar to that recorded through the device in out-patients with asthma [2]. Studies in children [3] and adults [4] have found that similar bronchodilatation is achieved when terbutaline is inhaled from Turbuhaler at peak inspiratory flows around 30 and $60 \mathrm{~L} \cdot \mathrm{min}^{-1}$. Reduced but significant bronchodilatation is still seen at lower flows [3]. Virtually all $(98 \%)$ of our patients with acute asthma generated a PIF $>30 \mathrm{~L} \cdot \mathrm{min}^{-1}$ through Turbuhaler, and the efficacy of a bronchodilator drug administered this way would only be minimally compromised in the two patients who recorded $26 \mathrm{~L} \cdot \mathrm{min}^{-1}$.

Significant correlations were found between inspiratory and expiratory flow rates but these relationships were too weak to allow PIF to be predicted from PEF or FEV1. Correlation coefficients between PIF and both expiratory flow rates were very similar to those obtained by ENGEL et al. [2] in out-patients with asthma. They studied a similar number of adults who had less severe airway obstruction (mean FEV1 2.4 L) and found a weak relationship between expiratory flow rates and PIF through the Turbuhaler, as was found in our study. In contrast to the study by ENGEL et al. [2] we found that PIF was lower than PEF in patients with the most severe airways obstruction but, despite this and high resistance to airflow through the Turbuhaler, nearly all patients generated adequate inspiratory flow. PIF-T could not be predicted from age, sex or PIF measured without the device.

In this study, response to therapy delivered via Turbuhaler was not assessed. However, ToNNESEN et al. [5] suggest that this mode of terbutaline delivery may be more effective than taking the drug as aerosol via a large spacer in patients with acute asthma. Our study shows that the vast majority of adults with acute asthma can generate inspiratory flow through Turbuhaler sufficient to allow a therapeutically active amount of bronchodilator drug to be delivered to the airways.

\section{References}

1. Harvey J, Williams JG. Randomised cross-over comparison of five inhaler systems for bronchodilator therapy. Br J Clin Pharmacol 1992; 46: 249-251.

2. Engel T, Heinig JH, Madsen F, Nikander K. Peak inspiratory flow and inspiratory vital capacity of patients with asthma measured with and without a new dry powder inhaler device (Turbuhaler). Eur Respir J 1990; 3: 1037-1041.

3. Pedersen S, Hansen OR, Fuglsang G. Influence of inspiratory flow rate upon the effect of a Turbuhaler. Arch Dis Child 1990; 65: 308-319.

4. Engel T, Scharling B, Skovsted B, Heinig JH. Effects, side-effects and plasma concentrations of terbutaline in adult asthmatics after inhaling from a dry powder inhaler device at different inhalation flows and volumes. $\mathrm{Br} \mathrm{J}$ Clin Pharmacol 1992; 33: 439-444.

5. Tonnesen F, Laursen LC, Evald T, Stahl E, Ibsen TB. Bronchodilating effect of terbutaline powder in acute severe bronchial obstruction. Chest 1994; 105 (3): 697-700. 